\title{
BIM Related Innovation in Healthcare Precinct Design and Facilities Management
}

\author{
Giles Thomson
}

Department of Strategic Sustainable Development, Blekinge Tekniska Högeskola,

Karlskrona, Sweden and,

Sustainable Built Environment National Research Centre,

Curtin University of Technology, Perth, Australia

Göran Lindahl

Department of Architecture and Civil Engineering, Chalmers University of Technology, Gothenburg, Sweden

Ammar Shemery

Sustainable Built Environment National Research Centre,

Curtin University of Technology, Perth, Australia

Mattias Roupé

Department of Architecture and Civil Engineering,

Chalmers University of Technology, Gothenburg, Sweden

Keith Hampson

Sustainable Built Environment National Research Centre,

Curtin University of Technology, Perth, Australia

Mikael Johansson

Department of Architecture and Civil Engineering,

Chalmers University of Technology, Gothenburg, Sweden

\begin{abstract}
Purpose - The purpose of this paper is to introduce and discuss potential applications of emerging Building Information Model (BIM) and related technologies as applied to healthcare facilities. The paper presents example of applications of digital tools enabled by BIM that support more integrated outcomes for complex healthcare projects.

Approach - Paper formulation by a transdisciplinary author group with ideas and approaches developed through discussions and writing to explore future research directions. Initial ideas are supplemented by a literature review with examples introduced where relevant.
\end{abstract}

(C) Giles Thomson, Göran Lindahl, Ammar Shemery, Mattias Roupé, Keith Hampson, Mikael Johansson. Published in the Emerald Reach Proceedings Series. Published by Emerald Publishing Limited. This article is published under the Creative Commons Attribution (CC BY 4.0) licence. Anyone may reproduce, distribute, translate and create derivative works of this article (for both commercial and non-commercial purposes), subject to full attribution to the original publication and authors. The full terms of this licence may be seen at http://creativecommons.org/licences/by/4.0/ legalcode

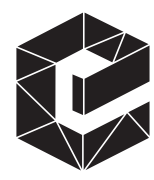

Emerald Reach Proceedings Series Vol. 2 Emerald Publishing Limited DOI 10.1108/S2516-285320190000002036 
10th Nordic Conference Tallinn
Findings - BIM as a front-end construction engineering tool is quite mature. Application of BIM and related tools to support complex healthcare at the precinct scale, for facilities management (FM), including improved user experience (UX) has been limited but shows great promise to support complex healthcare projects.

Research Limitations/Implications - The research presented is limited and exploratory as it represents the first step by this group to investigate an integrated approach to digital healthcare design and FM.

Practical Implications - The paper introduces the considerable benefits of BIM models, and related tools for FM and/or UX (both staff and patients) to save time, money and improves efficiency and accuracy in healthcare facilities.

Originality/Value - The transdisciplinary author group brought broad perspectives to the potential benefits of combining accurate data-rich legacy building models with other digital tools for increased integration and co-ordination at all life stages of a healthcare precinct.

Keywords Digital innovation, Healthcare, Precinct planning, Facilities management, BIM, PIM

All papers within this proceedings volume have been peer reviewed by the scientific committee of the 10th Nordic Conference on Construction Economics and Organization (CEO 2019).

\section{Introduction: the challenges for healthcare facilities}

Following the 2007 global financial crisis (GFC), several major hospitals and healthcare projects in Europe were postponed or even abandoned. Since 2007 investment in the sector has been steadily increasing but the High-Level Task Force on Investing in Social Infrastructure in Europe identify and refer to emergence of 'a huge investment gap in healthcare (European Hospital and Healthcare Federation, 2018). The healthcare investment gap is further complicated by other demands such as the increasing complexity, scale, regulatory and user experience (UX) demands as well as societal requirements that are now common in large healthcare projects.

This paper introduces some ways that emerging digital technologies based on BIM can help save costs and improve outcomes to meet gaps in the sector. The paper focusses on buildings and facilities, which serve as the venues and infrastructure for the provision of healthcare services. Appropriate design and functions support healthcare provision, conversely poor healthcare facility design adversely affect patients, staff and visitors. Healthcare developments such as person-centred care, patient empowerment, development of intermediate care functions, new technologies, etc. are driving developments related to the UX and function of facilities. There is a great need for innovation in healthcare design. Just as the medical profession demands rigorous scientific studies to verify evidence based medicine, the healthcare profession is increasingly demanding evidence based design for their physical environments (Hamilton et al., 2008). Rigorous research is the means through which we hold design accountable for its impact on health and well-being (Fache and Fache, 2014). Key areas requiring further attention in healthcare facility design, relating to user experience, were revealed through a broad literature review by Ulrich, Zimring et al. (2008), include

- patient safety issues, such as infections, medical errors and falls;

- other patient outcomes, such as pain, sleep, stress, depression, length of stay, spatial orientation, privacy, communication, social support and overall patient satisfaction; and

- staff outcomes, such as injuries, stress, work effectiveness and satisfaction.

If we add to the above the wider needs of FM the demands upon healthcare facilities becomes overwhelming for any one individual, or even a specialised organisational 
department to manage. Innovation is necessary to improve the experience for all users whether they are patients, staff, contractors, facilities managers or visitors to healthcare and medical precincts. To function well, large healthcare facilities need the input of multiple, sometimes contradicting, stakeholders to capture and synthesise their various requirements.

Increased co-ordination and innovation may be facilitated by BIM, which provides opportunities to streamline oft competing design objectives and technical requirements. More than this, virtual models can function as a platform to engage medical and operational staff in facility co-design. Thus, digital tools become enablers of evidence-based design Innovation outcomes to optimise healthcare facilities, benefiting patients, staff and visitors alike. BIM also creates a very powerful database for continuous development of the facility as well as enabling sharing of concepts and solutions amongst stakeholders. If connected to an open database, it could also be part of a larger agglomeration of information, experiences and effects data (Månsson et al., 2016; Månsson and Lindahl, 2016).

The following sections offer a brief overview to several emergent BIM related digital technologies driving innovation in the delivery and management of complex healthcare facilities over the whole asset life. The paper describes the opportunities of BIM and related tools to healthcare under the following thematic headings:

- healthcare buildings;

- healthcare precincts;

- healthcare facilities management; and

- healthcare collaborative design.

\section{Method}

The paper developed out of exploratory discussions from a transdisciplinary author group exploring the question "how can BIM and related tools deliver more integrated outcomes for healthcare projects". Authors represent construction management, architecture, modelling, planning, design, sustainability and FM expertise. Initial ideas were supplemented by a literature review with reference case studies from authors' prior work introduced where relevant. This paper will inform a future research agenda.

\section{Healthcare buildings}

While investment in most Nordic countries post-GFC decreased, Australia, which largely avoided the economic downturn, has built several major hospital projects, notably the Perth Children's Hospital (PCH) (\$US870 million) and the new Royal Adelaide Hospital (\$US1.2 billion), both using BIM to co-ordinate complex construction programs (Boton and Forgues, 2018; Sanchez et al., 2015).

Building Information Modelling (BIM) ... is a socio-technical system ... promises the ability to create models that combine data which was traditionally spread across multiple documents and databases along with the ability to share information between different models. (Sanchez et al., 2017, p. 45)

The common data environment of BIM allows sharing of information between different models and different users in complex projects, like healthcare facilities. The PCH (construction from 2015-2017) used BIM for faster information exchange increasing the hospital's overall design and construction efficiency, and minimising design conflicts (Sanchez et al., 2015). The post-construction digital legacy model, with structured data in a single database, is now being used for asset management throughout the hospital lifecycle (Thomson et al., 2017). 
10th Nordic

Conference Tallinn

458

\section{Healthcare precincts}

BIM is a virtual building model, but expansion of BIM models to include multiple buildings and infrastructure enables the modelling of whole neighbourhoods or precincts. As many healthcare facilities are part of larger complexes this becomes relevant to consider. The use of BIM, at a scale larger than individual buildings is in its infancy, but early precinct-scale models are known as Precinct Information Modelling (PIM). A PIM is a comprehensive 3D digital model that contains all the information needed to support planning, design, development, construction, management, operation, use and retrofitting of urban precincts (Newton et al., 2013).

PIM permits iterative co-design approaches for prototyping options and scenarios. Virtual models allow designs to be optimised before construction of a project begins (Pettit et al., 2014). By spending more time at the front end of a project design can deliver improved performance, while difficult to quantify, inevitably result in cost savings through a range of means e.g. reduced resource use, improved work practice co-ordination, improved worker efficiency and improved safety.

Digital planning tools, while still being developed, demonstrate great potential for improved integration of asset maintenance and management with large and complex healthcare precincts, to and the function and performance of entire facilities.

\section{Healthcare facilities management}

While the role of BIM in design and construction management of buildings has reached a degree of maturity, its application to FM is limited. FM developed as a discipline to address the combined pressures for lower operational cost, while ensuring facility construction, management and maintenance without compromised performance (Shohet and Lavy, 2004).

BIM information generated and captured during the lifecycle of a facility can be used in FM (Kassem et al., 2015). However, it is important the "as-built" model passes from the contractors to the facilities manager at project closeout, critically the accuracy of the model will ensure its usefulness (Lin et al., 2018). Shohet and Lavy (2004) describe the following five supporting domains of healthcare FM as

- development;

- maintenance management;

- supply services management;

- risk management; and

- performance management.

Precinct scale PIM represents the next wave of digital innovation for healthcare FM and operations management. Operations management at the larger precinct scale can lead to facility's resource optimisation, cost effectiveness and long term sustainability. BIM can be used for the modelling of energy, water and waste systems and as a central repository for improved monitoring and management of material and resource flows. In this way offering a decision support function to optimise energy and resources consumption (Wong and Fan, 2013).

Zadeh, Xuan and Shepley (2016) demonstrate that due to the complexities associated with medical work practices healthcare facilities typically lag behind more conventional structures in terms of sustainability performance. Zadeh, Xuan and Shepley (2016) also highlight the need for greater emphasis upon sustainability within healthcare facility design, not from an environmental ethics standpoint, but rather from a business perspectiveto remain competitive by reducing costs and supporting a health and well-being mission. 
Yet this burgeoning ecosystem of digital tools risks interoperability issues (Chen et al., 2018; Santos and Costa, 2017). For this reason good standards, i.e. a "baseline to which all operators should perform" (Evans, 2017) must be adhered to. A solution for overcoming interoperability between BIM software and FM software, could involve data mapping engines to dynamically deliver information from BIM models to FM systems (Chen et al., 2018).

In major projects, clients can play a significant role as drivers of innovation. This is particularly true when it comes to benchmarking to across "whole-of-asset lifecycle", monitoring with a benefits management framework is a useful tool to demonstrate the benefits and value delivered through the adoption of digital technologies (Hampson et al., 2017).

We have discussed some of the benefits that BIM and PIM offer in terms of facilities management, but gaming technology combined with BIM presents the potential for greatly enhanced collaborative design to benefit user experience as described in the next section.

\section{Healthcare collaborative design - a case study}

$\mathrm{BIM}$ provides the $3 \mathrm{D}$ visualisation of all objects in a facility, data linked to each object creates a data repository. This permits the use of the model for the analysis and assessment of maintenance and operation needs. Augmented reality can supplement the reality (facility) with data-rich components of virtuality (BIM) (Irizarry et al., 2014).

Chalmers University is integrating BIM models with gaming technology and virtual reality (VR). This integration of BIM with tools usually associated with other businesses enables a novel approach to establishing the design and subsequent design of the actual BIM model for use along the design and construction and management phase. In the conceptual design phase gaming technology speeds up visualisation techniques, permitting end users (e.g. doctors and nurses) to explore the design proposal inside the model in real time thus creating the first BIM model in the process of defining the future FM model. It greatly improves the communication of initial design concepts and features to consultants without getting lost in translation ( $c f$. using construction drawings to communicate with non-design literate stakeholders).

The collaborative design system uses a seamlessly connected multi-touch table and several VR-systems for supporting interactive and collaborative design (Elf et al., 2015). The system, as an example of application in a project's conceptual phase, was used to facilitate a design workshop as part of an ongoing hospital design. The workshop involved two different design tasks

- to design an operating theatre in a standard sized room (approx. $8 \times 9$ meters / $63 \mathrm{~m}^{2}$ ) and

- one room of extended size (approx. $10 \times 9$ meters $/ 82 \mathrm{~m}^{2}$ ).
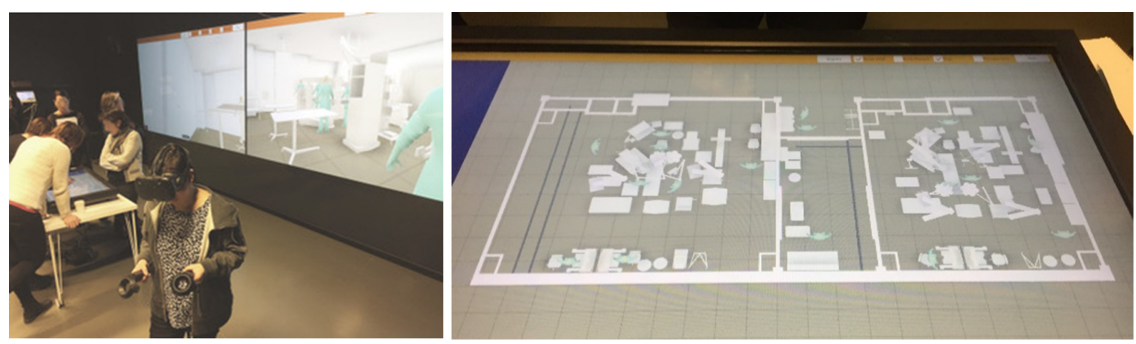

BIM Related Innovation

459

Figure 1.

During the

Workshop, three

HMD-system were

Seamlessly used

Together with the

Multi-Touch Table and Non-immersive

VR Controlled by a

Game Controller.

The Layout of

the Multi-touch

Table Screen and the Result from the Workshop. Available BIM-components are

Accessible from a

Scrollable Panel on the Left Side, and are Added to the Scene Using Dragand-Drop. 
10th Nordic Conference Tallinn
The participants started with the standard-sized room, the original room size having been decided by the project manager and designers. From the architects and the project manager point of view, it was important to stick to this standard sized room. However, during the workshop it was recognised by all the participants that the standard sized room was too small for the logistics of surgery. The nurses brought their medical practice expertise into the workshop to refine the architect's and project manager's original specification of a smaller operating theatre room. During this process, they built shared understanding and collaboratively recognised the value of a larger operating theatre room. The architect and project manager gained a deeper understanding of the nurses working situation and they continued to design the larger room together. The first iteration resulted in a room that was too large, a subsequent revision using the interactive multi-touch board interface allowed a room size reduction to approx. $8.9 \times 9$ meters $\left(c a .71 \mathrm{~m}^{2}\right)$. The architect stressed that this new room no longer fit the overall design of the building and therefore may not be possible. The visualisation process allowed one of the nurses to highlight that the operation preparation room located between the two operating theatres was too big, with the support of the collaborative design system they manged to narrow the width by one meter. The participants, discussed, validated and tested the new smaller preparation room in the VRsystem and reached a consensus that the new room worked. The revised design had two enlarged operating theatres with a smaller preparation room that fit into the overall building design to the satisfaction of the architect.

In this process the resolution and solution to the design problem emerged and the pursuit of a design solution that addressed the fit of the room in a building context. A traditional design process involves the architect interpreting users' ideas into a graphic representation, by contrast the technological setting (the BIM, multi-touch table, VR) of the presented collaborative design system, enables active engagement of users in design as well as establishing the first BIM model of a building to be. If in a refurbishment project there is already a BIM model the approach described will base its work on an existing model. It was also noted that the knowledge and experience transfer from the healthcare staff was better with the collaborative design system. Furthermore, the participants from the healthcare staff perceived that the tools gave a better understanding of the design and planning of physical spaces and that their professional skills were presented and extracted in a better way. Thus, the knowledge built into the model is much more robust. In addition to the articulation of user's knowledge there are also possibilities to make use of external consultants more efficiently and feed more developed requirements into the design process.

This is just one example demonstrating the potential for BIM to save money and improve design outcomes for users and patients in healthcare.

\section{Conclusions}

This paper sought to describe some ways that BIM and related tools can drive much needed innovation in healthcare facilities to resolve some competing demands, not only during construction, but also for FM and UX over the whole of asset life. Resolution of issues and/or testing in the model saves time and money, while improving the quality of the final product.

The use of digital tools in the asset management of the built environment, while emergent is evolving rapidly. To maximise the potential of these emerging tools, consistency and systematic studies and development is needed. Currently interoperability between tools, systems and even disciplines (e.g. construction versus FM) has reduced the industry uptake. The more complex the project the greater the benefits of BIM related systems. Major healthcare facilities represent some of the most complex construction 
projects in the world; therefore, overcoming limiting factors of BIM can be expected to greatly increase the use these systems in the healthcare sector

To date BIM standards have focused upon streamlining design and construction stages, without addressing the full potential for BIM, PIM and other digital tools for facilities management and, not least, operations management. The opportunity for further research in this area to optimise the design, performance and management processes of large healthcare facilities is significant. Such research needs to investigate integration standards for the broader eco-system of BIM related tools to ensure greater interoperability, and to maximise ease of use. The integration of BIM along the whole chain, or loop, from investigation and evaluation to operation and maintenance is today a vision that over the coming years will become more and more feasible. To understand how to utilise this development and its benefits will be crucial to an effective and sustainable construction, real estate sector. This in turn will translate to a range of improved efficiencies across healthcare assets such as reduced construction and operation costs, improved sustainability, and more importantly, enhanced patient and worker environments.

\section{References}

Boton, C. and Forgues, D. (2018), "Practices and Processes in BIM Projects: An Exploratory Case Study”, Advances in Civil Engineering, Vol. 2018, available at: https://doi.org/10.1155/2018/ 7259659 .

Chen, W., Chen, K. and Cheng, J. (2018), "Towards an Ontology-based Approach for Information Interoperability Between BIM and Facility Management”, in Smith, I. and Domer, B. (Eds.), Advanced Computing Strategies for Engineering. EG-ICE 2018. Lecture Notes in Computer Science, Vol 10864, Springer International Publishing, pp. 447-469.

Elf, M., Fröst, P., Lindahl, G. and Wijk, H. (2015), "Shared decision making in designing new healthcare environments - time to begin improving quality", BMC Health Services Research, Vol. 15, No. 144.

European Hospital and Healthcare Federation. (2018), "Capital investment in hospitals and healthcare services", Brussels, Belgium.

Evans, B. (2017), "Australia's forward momentum towards Industry 4.0 is fast and furious. But when change is the only constant, it helps to have something keeping you grounded .", Create, available at: https://www.createdigital.org.au/industry-engineering-standards-relevance/ (accessed 22 August 2018).

Fache, C. and Fache, F. (2014), "Current Trends in Health Facility Planning, Design and Construction", Frontiers of Health Service Management, Vol. 31, No. 1.

Hamilton, D. K., Diane, R. and Raboin, W. E. (2008), "Organizational transformation: a model for joint optimization of culture change and evidence-based design.", Herd, Vol. 1, No. 3, p. 40.

Hampson, K., Akhurst, P., Sanchez, A., Brooks, J., Smith, R., Shemery, A., Mohamed, S., et al. (2017), Whole-of-Life Value of Constructed Assets through Digital Technologies - Final Industry Report, Perth, Australia.

Irizarry, J., Gheisari, M., Williams, G. and Roper, K. (2014), "Ambient intelligence environments for accessing building information: A healthcare facility management scenario", Facilities, Vol. 32, No. 3, pp. 120-138.

Kassem, M., Kelly, G., Dawood, N., Serginson, M. and Lockley, S. (2015), "BIM in facilities management applications: A case study of a large university complex", Built Environment Project and Asset Management, Vol. 5, No. 3, pp. 261-277.

Lin, Y. C., Lin, C. P., Hu, H. T. and Su, Y. C. (2018), "Developing final as-built BIM model management system for owners during project closeout: A case study", Advanced Engineering Informatics, Elsevier, Vol. 36 No. February, pp. 178-193. 
10th Nordic Conference Tallinn
Månsson, D. and Lindahl, G. (2016), "BIM Performance and Capability", in Sanchez, A., Hampson, K. D. and Vaux, S. (Eds.), Delivering Value with BIM: A Whole-of-Life Approach, Routledge, London, UK.

Månsson, D., Sanchez, A., Hampson, K. and Lindahl, G. (2016), "Assessing BIM Performance Through Self-Assessed Benchmarking", Proceedings from CIB World Building Congress 2016, Tampere, Finland.

Newton, P., Marchant, D., Mitchell, J., Plume, J., Seo, S. and Roggema, R. (2013), Performance Assessment of Urban Precinct Design A Scoping Study, Co-operative Research Centre for Low Carbon Living, Sydney, Australia.

Pettit, C. J., Glackin, S., Trubka, R., Ngo, T., Lade, O., Newton, P. and Newman, P. (2014), “A co-design prototyping approach for building a Precinct Planning Tool", ISPRS Annals of Photogrammetry, Remote Sensing and Spatial Information Sciences, Vol. II-2 No. October, pp. 47-53.

Sanchez, A., Hampson, K. and London, G. (2017), "Integrating Information in Built Environments", in Sanchez, A., Hampson, K. and London, G. (Eds.), , Routledge, London, UK, p. 284.

Sanchez, A., Hampson, K. and Mohamed, S. (2015), Perth Children's Hospital, Case Study Report, Perth, Australia.

Santos, R. and Costa, A. A. (2017), "Information integration and interoperability for BIM-based lifecycle assessment", in Sanchez, A., Hampson, K. and London, G. (Eds.), Integrating Information in the Built Environment, Routledge, London, UK, pp. 91-108.

Shohet, I. M. and Lavy, S. (2004), "Healthcare facilities management: State of the art review", Facilities, Vol. 22, No. 7, pp. 210-220.

Thomson, G., Hampson, K. and Newman, P. (2017), "New technologies and processes for infill development”, in Rowley, S., Ong, R. and James, A. (Eds.), Perth's Infill Housing Future: Delivering Innovative and Sustainable Housing, Curtin University, Perth, Australia, pp. 93-118.

Ulrich, R. S., Zimring, C., Zhu, X., Dubose, J., Hyun-bo, S., Young-Seon, C., Xiaobo, Q., et al. (2008), “A review of the research literature on evidence based healthcare design", HERD: Health Environments Research \& Design Journal, Vol. 1, No. 3, pp. 61-125.

Wong, K. and Fan, Q. (2013), "Building information modelling (BIM) for sustainable building design", Facilities, Vol. 31 No. 3/4, pp. 138-157.

Zadeh, R., Xuan, X. and Shepley, M. (2016), "Sustainable healthcare design: Existing challenges and future directions for an environmental, economic, and social approach to sustainability", Facilities, Vol. 34 No. 5/6, pp. 264-288. 